\title{
Inhibition of Invasion by Polyphenols from Citrus Fruit and Berries in Human Malignant Glioma Cells In Vitro
}

\author{
HARCHARAN KAUR ROOPRAI ${ }^{1}$, MARIA CHRISTIDOU $^{2}$, SAMANTHA ANGEL MURRAY $^{2}$, DEREK DAVIES $^{3}$, \\ RICHARD SELWAY ${ }^{1}$, RICHARD W. GULLAN ${ }^{1}$ and GEOFFREY J. PILKINGTON ${ }^{2,4}$ \\ ${ }^{1}$ Department of Neurosurgery, King's College Hospital, London, U.K.; \\ ${ }^{2}$ School of Pharmacy and Biomedical Sciences, University of Portsmouth, Portsmouth, U.K.; \\ ${ }^{3}$ Flow Cytometry Facility, The Francis Crick Institute, London, U.K.; \\ ${ }^{4}$ Department of Basic and Clinical Neuroscience, King's College London, London, U.K.
}

\begin{abstract}
Background/Aim: The outlook for patients with high grade glioma $(H G G)$ remains dismal. Hence, attention has focused on numerous innovative treatments. Our group has proposed a strategy on the use of a combination of polyphenols, as anti-invasive agents for the management of these neoplasms. Materials and Methods: The aim of this study was to evaluate the in vitro effects of citrus flavonoids (tangeretin, nobiletin, naringin and limonin) and berry extracts (chokeberry, elderberry and bilberry) on selected mediators of invasion in 2 HGG cell cultures. Results: The $I C_{50}$ values could only be determined for tangeretin and chokeberry extract. The rest were non-functional in this context. Immunocytochemistry and flow cytometry results showed that chokeberry extract was most effective in downregulating the expression of CD44. Similarly, RT-PCR data supported its ability to reduce gene expression of MMP-14 and EGFR. 2D invasion assays confirmed that inhibition is greater with chokeberry extract. Conclusion: Both polyphenols have anti-invasive potential but chokeberry extract is a stronger agent for glioma management.
\end{abstract}

The most frequent forms of high-grade glioma (HGG) are anaplastic astrocytoma (AA, grade III) and glioblastoma multiforme (GBM, grade IV) (1). Despite the fact that current conventional treatment includes maximal surgical resection followed by radiotherapy with concomitant and adjuvant

This article is freely accessible online.

Correspondence to: Professor Geoffrey J. Pilkington, School of Pharmacy and Biomedical Sciences, University of Portsmouth, Portsmouth, PO1 2DT, U.K. Tel: +44 (0)7768523602, e-mail: Geoff.pilkington@port.ac.uk

Key Words: Gliomas, tangeretin, Aronia melanocarpa, invasion, matrix metalloproteases. chemotherapy (Temozolomide), the median survival time for AA and GBM is 24 months and 14.6 months, respectively (2). This dismal prognosis is due to their cellular heterogeneity, which renders them resistant to radio- and chemo-therapies, as well as to the infiltrative tumour cell invasion into the brain parenchyma, which results in tumour progression and recurrence. Thus, invasion not only precludes successful therapy, but is also the main cause of death of these patients.

Glioma cell invasion is well documented and involves a complex multistep process. Mediators or regulators of invasion include cell adhesion molecules such as integrins and the hyaluronan receptor, cluster of differentiation 44 (CD44); extracellular matrix (ECM) components e.g. hyaluronic acid (HA) and laminin; proteases such as matrix metalloproteases (MMPs), and their inhibitors (Tissue inhibitors of MMPs or TIMPs), as well as growth factors and cytokines $(3,4)$. Furthermore, amplification and over-expression of the receptor tyrosine kinase, epidermal growth factor receptor (EGFR) have been implicated in the downstream signalling events of glioma cell invasion and angiogenesis. These include activation of two major signalling pathways: Ras/MAPK/ERK (mitogen-activated protein kinases) and Ras/PI3K/AKT (phosphatidylinositol 3-kinase). Additionally, a mutant form of EGFR, known as EGFRvIII is over-expressed in GBMs and has been associated with poor prognosis (5).

HGGs remain incurable. Hence, there is still a strong need for new adjuvant therapeutic intervention to combat these neoplasms with minimal toxicity to normal cells. Over the last three decades, numerous innovative treatments have been reported including targeted therapies (6). Since the major research interest of our group has, over several decades, been glioma invasion, we proposed one such strategy previously based on the therapeutic potential of a combination of naturally occurring micronutrients (including polyphenols) for the management of malignant brain tumours: the "Nutraceutical Approach" (7). This proposed approach is based on the ability of these anti-cancer agents 
(e.g. citrus flavonoid, tangeretin from tangerine peel) to interfere with the mechanisms underlying brain tumour invasion (8). Our group has previously reported the inhibition of invasion and induction of apoptosis by selenium in an HGG-derived cell line (IPSB-18) (9). Furthermore, we have also shown that curcumin (CUR), a curcuminoid (a polyphenolic compound from turmeric) and Aronia melanocarpa (chokeberry extract) can induce apoptosis in an established GBM cell line, U373 (10).

In recent years, there has been an increased interest in flavonoids and the induction of apoptosis in cancer cells (11). Numerous reports in the literature have identified various micronutrients and combinations of polyphenols which have multiple therapeutic targets in cancer, $(12,13)$ and specifically in malignant brain tumour cells $(14,15)$.

Although the term "Nutraceutical" was introduced over 3 decades ago to designate a link between nutrition and pharmaceutical agents, there is still no universally accepted definition for it. However, it covers a wide range of naturally occurring products and dietary supplements including polyphenols, which are divided into flavonoids (e.g. flavones, anthocyanidins) and non-flavonoids (e.g. phenolic acid). The basic structure of a flavonoid comprises two benzene rings linked through a heterocyclic pyran or pyrone (with a double bond) ring in the middle. Polyphenols can have one or more hydroxyl groups attached to a benzene ring.

To the best of our knowledge, our group was the first to report the anti-glioma potential of flavonoids. Subsequently, as a part of a bigger study, we screened various polyphenolic compounds to find a suitable combination to be tested in our Nutraceutical clinical trial. Preliminary data from KaplanMeier survival curves suggested a non-statistically significant survival advantage for GBM patients who received the combination (16). However, the data and outcome of the trial are currently being fully evaluated.

The aim of this study was to investigate the invasive potential of 4 citrus flavonoids (tangeretin, nobiletin, naringin and limonin) and polyphenolic compounds from 3 berry extracts (chokeberry, elderberry and bilberry) in 2 HGG-derived in vitro cell cultures, in order to select the best candidates for therapeutic intervention.

\section{Materials and Methods}

Polyphenols. The polyphenols used in this study were from citrus fruit including tangeretin (a citrus methoxyflavone), nobiletin (a citrus polymethoxyflavone), naringin (a flavanone) and limonin (a limonoid) (Figure 1A-D). These were provided by the Department of Citrus, Tampa, Florida, USA. Polyphenolic compounds from berries including chokeberry extract (Aronia melanocarpa), elderberry extract (Sambucus nigra) and bilberry extract (Vaccinum myrtilus) were provided by Artemis International Inc. Indiana, USA, who have also supplied them to other cancer researchers too. These purified extracts contain a phenolic acid (chlorogenic acid), catechins, rutin (a flavone) and various anthocyanins (Figure 1E-I and Table I).

Tissue specimen. Two surgical samples from patients with GBM and AA were obtained during craniotomy from the Neurosurgical staff at King's College Hospital, London, under local Ethical permission (LREC No 00-173). Biopsy material was used to establish shortand long-term cell cultures: IPTP (GBM) and IPSB-18 (AA), respectively. The latter is now well characterised (17). These brain tumour samples were diagnosed by a neuropathologist, according to the World Health Organisation (WHO) criteria. In addition, 2 surgical samples from an epileptic patient were obtained during temporal lobectomy and used to derive human non-neoplastic astrocytic cultures (IPLD and UPES). These were used as controls in this study.

Cell culture. Both glioma cultures and normal astrocytic cells were maintained in complete medium: Dulbecco's Modified Eagle's Medium (DMEM, Gibco, Fisher Scientific, Loughborough, UK) supplemented with $10 \%(\mathrm{v} / \mathrm{v})$ of heat-inactivated foetal calf serum (Sigma-Aldrich, Dorset, UK) and 1\% antibiotic/antimycotic solution (Sigma-Aldrich) at a final concentration of $100 \mathrm{IU}$ penicillin, 100 $\mu \mathrm{g}$ amphotericin per $\mathrm{ml}$. Cells were routinely propagated as monolayers in small plastic culture flasks in a standard humidified incubator at $37^{\circ} \mathrm{C}$ with $5 \% \mathrm{CO}_{2}$. The complete medium was changed every few days. Subculturing was carried out by washing cells with Hank's balanced salt solution (HBSS, Gibco, Fisher Scientific, Loughborough, UK) followed by incubation with $1 \mathrm{mM}$ Trypsin (Sigma-Aldrich).

Additionally, for 2D invasion assays, serum free medium (SFM) was prepared from Dulbecco's MEM F-12 (Ham) nutrient mix (Gibco, Fisher Scientific, Loughborough, UK) supplemented with $0.5 \%$ 3'3'5'-Triiodo-L-thyronine (15 nM) (Sigma-Aldrich), $1 \%$ Insulin $(5 \mu \mathrm{g} / \mathrm{ml})$-transferrin $(5 \mu \mathrm{g} / \mathrm{ml})$-sodium selenite $(5 \mathrm{ng} / \mathrm{ml})$ media supplement solution (Sigma-Aldrich), $1 \%$ L- Glutamine $(0.2$ M) with $1 \%$ Penicillin/Streptomycin (Sigma-Aldrich) and $1 \%$ 11 Progesterone at $20 \mu \mathrm{g} / \mathrm{ml}$ (Sigma-Aldrich).

MTT viability assay. All the assays carried out in the study were contingent upon the initial determination of the $\mathrm{IC}_{50}$ values for various polyphenols in the glioma cells and normal astrocyte cultures. The MTT viability assay is based on the reduction of the tetrazolium salt MTT (3[4,5-dimethylthiazole-2-yl]-2,5-diphenyltetrazolium bromide) (Sigma-Aldrich) to insoluble formazan by the enzyme succinate dehydrogenase of viable mitochondria in cells (18). The blue formazan product is then dissolved in dimethyl sulphoxide (DMSO, Sigma-Aldrich) and the colour is quantified spectrophotometrically as an indicator of viable cells, on a Dynatech MR 700 microplate reader, at a wavelength of $570 \mathrm{~nm}$.

Briefly, cells were seeded on 96-well plates and left overnight to adhere before replacing the fresh medium containing each polyphenol at a small range of concentrations $(5 \mu \mathrm{g} / \mathrm{ml}-40 \mu \mathrm{g} / \mathrm{ml})$ in all 3 cell cultures initially and then, at a wider range $(1 \mu \mathrm{g} / \mathrm{ml}-$ $1000 \mu \mathrm{g} / \mathrm{ml}$ ) to study their possible cytotoxicity effects. The treated cells were incubated at $37^{\circ} \mathrm{C}$ for $48 \mathrm{~h}$. A positive control of untreated cells incubated with medium only, and a negative control with $0.1 \mathrm{M}$ Sodium Hydroxide (Sigma-Aldrich) were also included. The $\mathrm{IC}_{50}$ values for nobiletin, naringin, limonin, elderberry extract (Sambucus nigra) and bilberry extract (Vaccinum myrtilus) could not be determined as they exceeded $1,000 \mu \mathrm{g} / \mathrm{ml}$. This suggests that 
A<smiles>COc1ccc(-c2cc(=O)c3cc(OC)c(OC)c(OC)c3o2)cc1</smiles>

C<smiles>N#CCOc1cc(O)c2c(c1)OC(c1ccc(O)cc1)CC2=O</smiles>

E<smiles>O=C(/C=C/c1ccc(O)c(O)c1)Oc1cc(C(=O)O)cc(O)c1O</smiles>

G<smiles>Oc1cc(O)c2c(c1)OC(c1ccc(O)c(O)c1)[C@H](O)C2</smiles><smiles></smiles>

B<smiles>COc1ccc(-c2cc(=O)c3c(C=O)c(O)c(O)c(CO)c3o2)cc1OC</smiles>

D

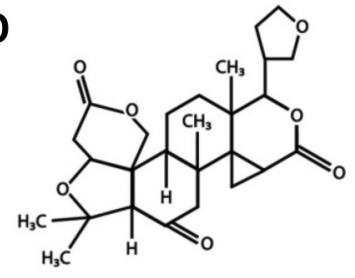<smiles>Oc1cc(O)c2c(c1)OC(c1ccc(O)c(O)c1)C(O)C2</smiles>

H<smiles>CCOc1c(-c2ccc(O)c(O)c2)oc2cc(O)cc(O)c2c1=O</smiles>

\section{$\mathrm{R}=$ arabinose $=$ Cyanidin-3-arabinoside $R=$ galactose $=$ Cyanidin-3-galactoside $R=$ glucose $=$ Cyanidin-3-glucoside}

Figure 1. Basic chemical structures of polyphenols used in the study. A) Tangeretin, B) nobiletin, C) naringin, D) limonin, E) chlorogenic acid, F) catechin, $G$ ) epicatechin, $H$ ) rutin, I) anthocyanin in which $R$ is variable.

they are non-functional in the context. Hence, all subsequent experiments were conducted with tangeretin and chokeberry extract (Aronia melanocarpa) only.

Immunocytochemistry (ICC). IPSB-18 (Passage 36), IPTP (Passage 10) and IPDL (Passage 4) cells were seeded at a density of $1 \times 10^{5} /$ well on sterile coverslips in complete medium within a 6 -well plate. They were treated with tangeretin or chokeberry extract at their respective $\mathrm{IC}_{50}$ values for $48 \mathrm{~h}$ and maintained in complete medium as described above. Controls were included in which either untreated cells were grown during the same time period or the primary antibody was omitted. Next, immunostaining was carried out by incubating cells with the primary antibody - mouse monoclonal CD44 (dilution of 1:100 HBSS) (Cymbus Biotechnology, UK) at room temperature for $1 \mathrm{~h}$, followed by incubation with a secondary antibody: anti-mouse biotinylated polyclonal antibody (1:100) (Dako, UK) for $30 \mathrm{~min}$ and streptavidin fluorescein (1:200) (Amersham, UK). The cells were then fixed and counterstained with propidium iodide. All specimen coverslips were mounted in Citifluor and examined using a Zeiss Universal microscope (Zeiss Pascal, LSM 5) incorporating reflected fluorescence with excitation and barrier filters for fluorescein isothiocyanate (FITC) and propidium iodide.

Flow cytometry (FC). CD44 positivity was also assessed quantitatively by flow cytometry in parallel with ICC for the same cell cultures and polyphenols described above. Cells $\left(1 \times 10^{6}\right)$ were grown in $75 \mathrm{~cm}^{2}$ flasks and treated with the selected polyphenols for $48 \mathrm{~h}$. After treatment, cells were harvested before incubating for $1 \mathrm{~h}$ with anti-mouse monoclonal CD44 antibody (dilution of 1:100 in Phosphate buffer saline, PBS) (Cymbus Biotechnology, UK). This was followed by incubation with the secondary antibody: 
Table I. List of main polyphenols present in chokeberry, Elderberry and Bilberry extracts: phenolic acids, catechins, a flavone and different anthocyanins.

\begin{tabular}{ll}
\hline Berry extract & Main polyphenols \\
\hline Chokeberry (Aronia Melanocarpa) & Phenolic acid: chlorogenic acid \\
& Catechins: (-)-epicatechin, (+)-catechin \\
& Flavone: rutin \\
& Anthocyanins: cyanindin-3-galactoside, cyanindin-3-arabinoside, cyanindin-3-xyloside \\
& Phenolic acid: chlorogenic acid \\
& Catechins: (-)-epicatechin, (+)-catechin \\
& Flavone: rutin \\
Elderberry (Sambucus Nigra) & cyanindin-3,5-diglucoside, cyanindin-3-sambubioside-5-glucoside \\
& Phenolic acid: chlorogenic acid, p-coumaric acid \\
& Catechins: (-)-epicatechin, (+)-catechin \\
& Flavone: rutin \\
Anthocyanins: cyanindin-3-glucoside, cyanindin-3-galactoside, cyanindin-3-arabinoside, \\
peonidin-3-glucoside, peonidin-3-galactoside, peonidin-3-arabinoside, delphinidin-3-glucoside, \\
delphinidin-3-galactoside, delphinidin-3-arabinoside, petunidin-3-glucoside, petunidin-3-galactoside, \\
petunidin-3-arabinoside, malvidin-3-glucoside, malvidin-3-galactoside, malvidin-3-arabinoside \\
\hline
\end{tabular}

FITC-conjugated polyclonal rabbit anti-mouse immunoglobin (1:100 in PBS) (Dako). In the corresponding positive control samples, the primary antibody was omitted. The analysis was carried out by using dead cell exclusion, by measuring fluorescence levels using a Becton-Dickinson FACS Calibur flow cytometer, with FITC fluorescence being measured using a 530/30 bandpass filter after $488 \mathrm{~nm}$ excitation.

RNA isolation. RNA isolation was carried out according to the established protocols in the laboratory (11). Briefly, in order to investigate the gene expression of various MMPs (MMP-2,-9,-14,$15,-16,-17,-24$ and -25) TIMPs (TIMP-1, -2, -3, and -4) and EGFR, quantitative Real-Time polymerase chain reaction (PCR) was performed when IPSB-18 and IPTP cells were treated for $48 \mathrm{~h}$ with the selected polyphenols at their respective $\mathrm{IC}_{50}$ values. Cells were then harvested using Cell Dissociation Solution (Sigma-Aldrich) before $2 \mathrm{ml}$ of RNAzol reagent (Biogenesis, UK) was added to the pellet.

Reverse transcription and quantitative real-time RT-PCR. Total RNA $(1 \mu \mathrm{g})$ was reverse transcribed using $2 \mu \mathrm{g}$ random hexamers (Amersham Biosciences, UK) and 200 units of Superscript II reverse transcriptase (Invitrogen Life Technologies, UK). Sequences for primers and probes used in this study (Table II) for 8 MMPs, 4 TIMPs and EGFR are also described elsewhere (19).

The 18S rRNA gene was used as an endogenous control to normalise for differences in the amount of total RNA in each sample. $18 \mathrm{~S}$ was TaqMan ribosomal RNA control reagents part no. 4308329 (Applied Biosystems, Warrington, UK). PCR reactions were performed using the ABI Prism 7700 Sequence Detection System (Applied Biosystems, Warrington, UK) as per the manufacturer's protocol. Each reaction was performed in $25 \mu \mathrm{l}$ and contained the equivalent of $5 \mathrm{ng}$ of reverse transcribed RNA (1 ng RNA for the 18S analyses), 50\% TaqMan 2X PCR Master Mix (Applied Biosystems), $100 \mathrm{nM}$ each of the forward and reverse primer, and $200 \mathrm{nM}$ of probe. Conditions for the PCR reaction were 2 min at $50^{\circ} \mathrm{C}, 10 \mathrm{~min}$ at $95^{\circ} \mathrm{C}$ and then, 40 cycles, each consisting of $15 \mathrm{~s}$ at $95^{\circ} \mathrm{C}$, and $1 \mathrm{~min}$ at $60^{\circ} \mathrm{C}$.

In order to determine the relative RNA levels within the samples, standard curves for the PCR reaction were prepared by using the cDNA from one sample and making two-fold serial dilutions covering the range equivalent to $20 \mathrm{ng}$ to $0.625 \mathrm{ng}$ of RNA (for $18 \mathrm{~S}$ analyses the range was from $4 \mathrm{ng}$ to $0.125 \mathrm{ng}$ ). These dilutions were subject to real-time PCR as described above. Relative standard curves for cycle threshold (CT) versus input RNA were prepared. Relative levels of starting RNA in each sample were determined. The results for each target mRNA were normalized to those from $18 \mathrm{~S}$ ribosomal RNA from the same sample. RNA from both IPSB18 and IPTP cell cultures was extracted using a PCR method to look at the gene expression of MMPs and their inhibitors, TIMPs as well as EGFR in the samples with or without the addition of either tangeretin or chokeberry extract, at concentrations corresponding to their respective $\mathrm{IC}_{50}$ values.

$2 D$ invasion assay. The invasive potential of monolayers of cells in vitro was evaluated using 24-well Transwell units with $8 \mu \mathrm{m}$ porosity polycarbonate membrane filters (Corning, Loughborough, UK) using a modification of the method described by Albini et al. (20). Briefly, the filters were coated with growth factor reduced Matrigel (Becton Dickinson, USA) and left overnight at $4^{\circ} \mathrm{C}$. Before use, each well in the Transwell unit was rehydrated with serum-free medium (SFM) for $1 \mathrm{~h}\left(37^{\circ} \mathrm{C}, 5 \% \mathrm{CO}_{2}\right)$. IPSB-18 and IPTP cells were grown in flasks, weaned down from complete medium to serum-free medium (SFM), harvested and seeded in the upper compartment of a Transwell at a density of $100,000 \mathrm{cells} / \mathrm{cm}^{2}$. The cells were treated with polyphenols at concentrations of their respective $\mathrm{IC}_{25}, \mathrm{IC}_{50}$ or $\mathrm{IC}_{75}$ values, while untreated cells were used as controls. The lower chamber was filled with complete medium supplemented with a chemoattractant, PDGF A/B (Sigma-Aldrich). After $8 \mathrm{~h}$ of incubation at $37^{\circ} \mathrm{C}$, cells on the upper side of the filter were wiped off. The cells on the bottom side were fixed with 
Table II. Sequences of PCR primers and sequence-specific probes for MMPs, TIMPs and EGFR targets used in this study.

TaqMan primers and probes

\begin{tabular}{|c|c|c|}
\hline \multirow[t]{3}{*}{ MMP-2 } & Forward primer: & 5'-TGGCGATGGATACCCCTTT-3' \\
\hline & Reverse primer: & 5'-TTCTCCCAAGGTCCATAGCTCAT-3' \\
\hline & Probe: & 5'-FAM-CTCCTGGCTCATGCCTTCGCCC-TAMRA-3' \\
\hline \multirow[t]{3}{*}{ MMP-9 } & Forward primer: & 5'-CCTGGGCAGATTCCAAACCT-3' \\
\hline & Reverse primer: & 5'-GCAAGTCTTCCGAGTAGTTTTGGAT-3' \\
\hline & Probe: & 5'-FAM-CTCAAGTGGCACCACCACAACATCACC-TAMRA-3' \\
\hline \multirow[t]{3}{*}{ MMP-14 } & Forward primer: & 5'-AGGCCGACATCATGATCTTCTTT-3' \\
\hline & Reverse primer: & 5'-AAGTGGGTGTCTCCTCCAATGTT-3' \\
\hline & Probe: & 5'-FAM-CCATGGCGACAGCACGCCCTT-TAMRA-3' \\
\hline \multirow[t]{3}{*}{ MMP-15 } & Forward primer: & 5'-ATGCGTTCCGCCCAGAT-3' \\
\hline & Reverse primer: & 5'-GCCGCTTCATCCACTCCTT-3' \\
\hline & Probe: & 5'-FAM-TCCCAGTCACCGGTGTGCTCGAC-TAMRA-3' \\
\hline \multirow[t]{3}{*}{ MMP-16 } & Forward primer: & 5'-ATGATTTACAGGGCATCCAGAAA-3' \\
\hline & Reverse primer: & 5'-TGGAGGCCGAGGAGGTTT-3' \\
\hline & Probe: & 5'-FAM-CAAGATT CCTCCACCTACAAGACCTCTACCGAC-TAMRA-3' \\
\hline \multirow[t]{3}{*}{ MMP-17 } & Forward primer: & 5'-GCGGGTATCCTTCCTCTACGTT-3' \\
\hline & Reverse primer: & 5'-CAGCGACCACAAGATCGTCTT-3' \\
\hline & Probe: & 5'-FAM-GTCCTTGAACACCCAGTACCTGTCTCCTTTAA-TAMRA-3' \\
\hline \multirow[t]{3}{*}{ MMP-24 } & Forward primer: & 5'-CCAGTACATGGAGACGCACAA-3' \\
\hline & Reverse primer: & 5'-TGCGGACGGGGAGTGT-3' \\
\hline & Probe: & 5'-FAM-CAGGGCATCCAGAAGATCTATGGACCC-TAMRA-3' \\
\hline \multirow[t]{3}{*}{ MMP-25 } & Forward primer: & 5'-GACGATGAGGAGACCTGGACTTT-3' \\
\hline & Reverse primer: & 5'-CCTGGTAGAAGGGCCTCATAATG-3' \\
\hline & Probe: & 5'-FAM-CCGACCTGTTTGCCGTGGCTGTC-TAMRA-3' \\
\hline \multirow[t]{3}{*}{ TIMP-1 } & Forward primer: & 5'-GACGGCCTTCTGCAATTCC-3' \\
\hline & Reverse primer: & 5'-GTATAAGGTGGTCTGGTTGACTTCTG-3' \\
\hline & Probe: & 5'-FAM-ACCTCGTCATCAGGGCCAAGTTCGT-TAMRA-3' \\
\hline \multirow[t]{3}{*}{ TIMP-2 } & Forward primer: & 5'-GAGCCTGAACCACAGGTACCA-3' \\
\hline & Reverse primer: & 5'-AGGAGATGTAGCACGGGATCA-3' \\
\hline & Probe: & 5'-FAM-CTGCGAGTGCAAGATCACGCGC-TAMRA-3' \\
\hline \multirow[t]{3}{*}{ TIMP-3 } & Forward primer: & 5'-CCAGGACGCCTTCTGCAA-3' \\
\hline & Reverse primer: & 5'-ССССТССТTTACCAGCTTCTTC-3' \\
\hline & Probe: & 5'-FAM-CGACATCGTGATCCGGGCCA-TAMRA-3' \\
\hline \multirow[t]{3}{*}{ TIMP-4 } & Forward primer: & 5'-CACCCTCAGCAGCACATCTG-3' \\
\hline & Reverse primer: & 5'-GGCCGGAACTACCTTCTCACT-3' \\
\hline & Probe: & 5'-FAM-CACTCGGCACTTGTGATTCGGGC-TAMRA-3' \\
\hline \multirow[t]{3}{*}{ EGFR } & Forward primer: & 5'-CGTTTGGGAGTTGATGACCTTT-3' \\
\hline & Reverse primer: & 5'-GGCTGAGGGAGGCGTTCT-3' \\
\hline & Probe: & 5'-FAM-AGCCATATGACGGAATCCCTGCCAG-TAMRA-3' \\
\hline
\end{tabular}

methanol and stained with a Diff-quick differential staining kit (BDH, Poole, Dorset, UK) and mounted onto slides. Images were captured by a Zeiss Universal microscope. Cells were counted in both the upper side and those that had invaded to the lower side of the filter in 5 different fields, and the means \pm SD were calculated. Results were expressed as:

Invasion $(\%)=\frac{\begin{array}{c}\text { (Mean number of cells } \\ \text { on lower side of filter) }\end{array}}{\begin{array}{c}\text { (Mean total number of cells } \\ \text { on upper side of filter })\end{array}} \times 100$

$3 D$ invasion assay. It was only possible to further evaluate the invasive potential of tangeretin at its $\mathrm{IC}_{50}$ value, and not of the chokeberry extract. Spheroids of tumour cells (IPSB-18 and IPTP) as well as normal brain astrocytes (UPES) were constructed using a modification of the "hanging drop" method of the 3D invasion model (21). Briefly, monolayers of cell cultures were harvested and resuspended in complete medium. Thirty $\mu$ drops containing 45,000 cells/drop, were suspended from an inverted culture Petri dish lid and incubated at $37^{\circ} \mathrm{C}$ and $5 \% \mathrm{CO}_{2}$ for $24 \mathrm{~h}$. Complete medium or sterile water was added to the base of the dish. Then, the resulting aggregates were transferred into culture Petri dishes coated with a non-adhesive substrate $(2 \%$ Agar in distilled water and complete medium). These 2D aggregates formed 3D spheroids on agar after incubation for at least $24 \mathrm{~h}$. After 4 days, glioma spheroids (IPSB-18 or IPTP) were stained with fluorescent dyes and confronted with brain cell aggregates of normal astrocytes (UPES) to assess invasive activity. Confrontations with similar 
A

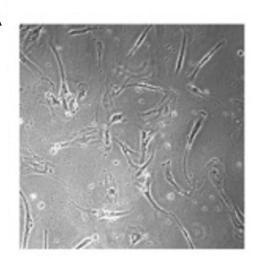

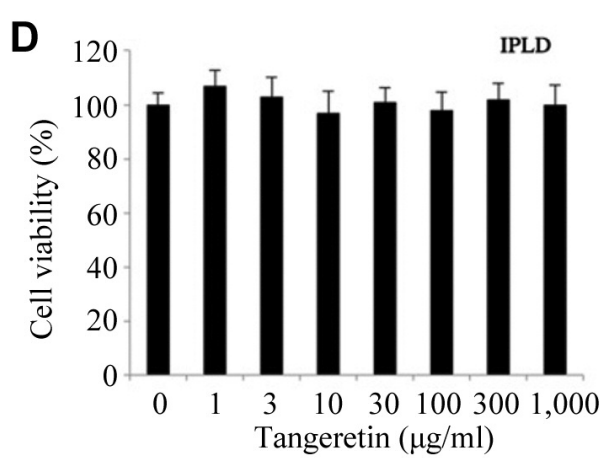

B

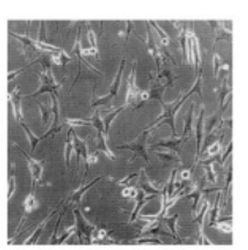

F

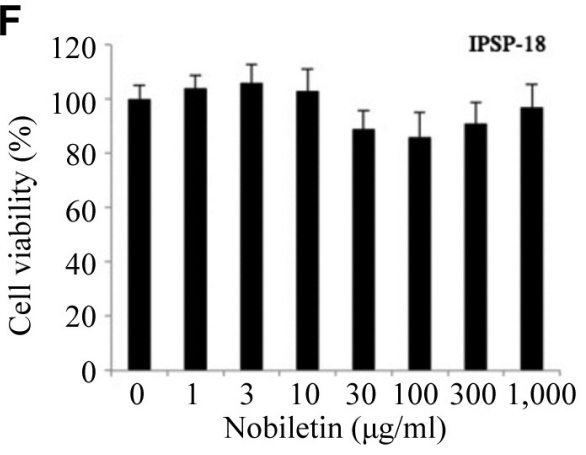

H

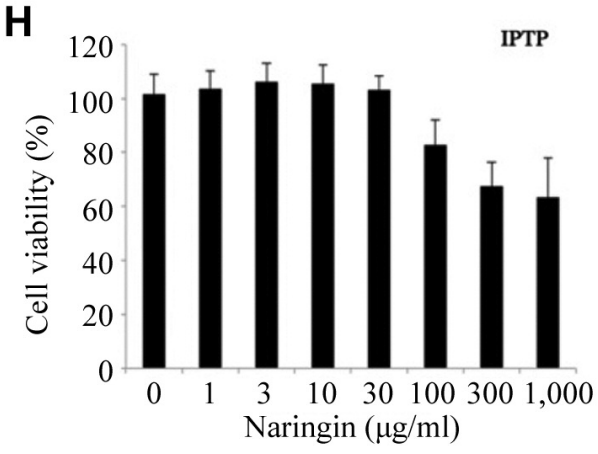

J

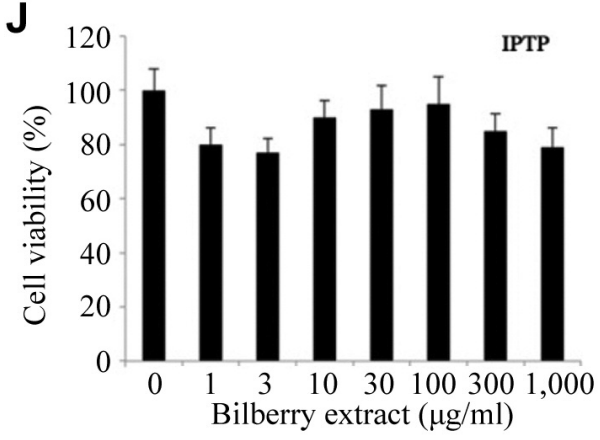

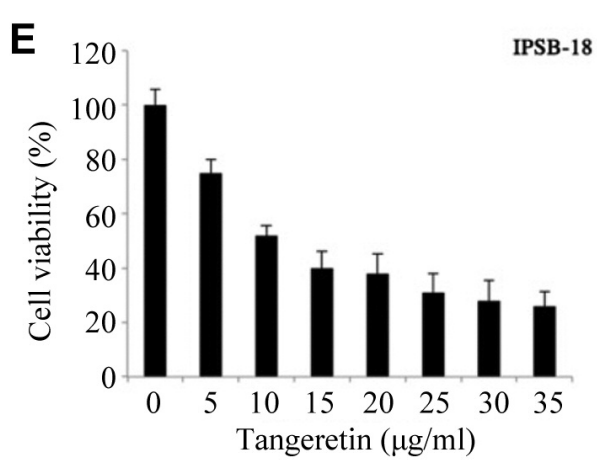

G

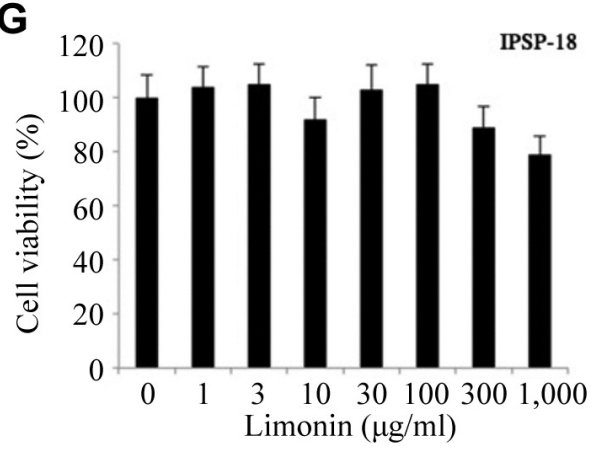

I
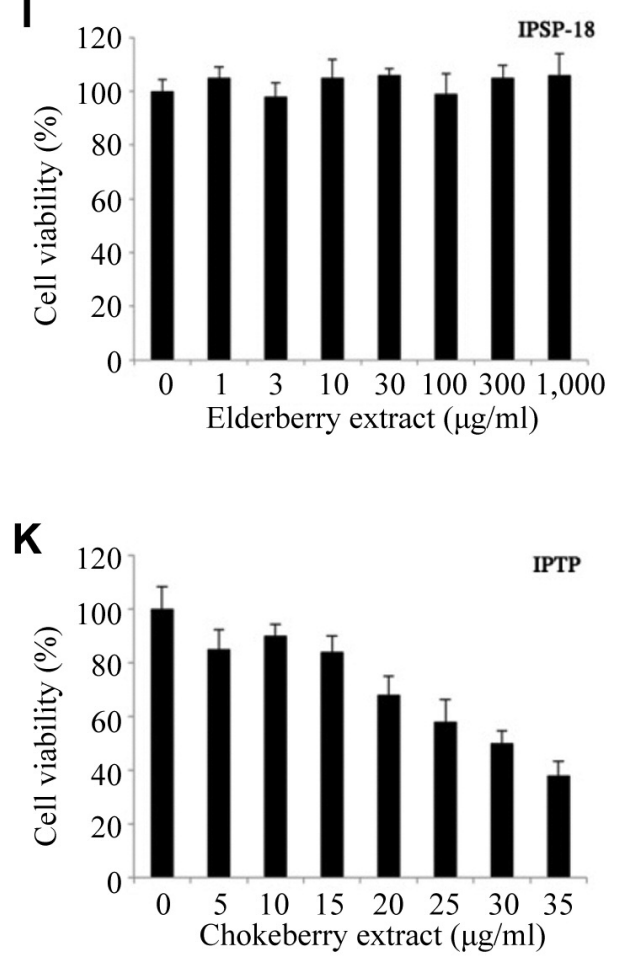

Figure 2. Effects of citrus flavonoids and berry extracts on the viability of HGG cells. Phase contrast micrographs of A) human astrocyte cells $I P L D, B)$ astrocytic astrocytoma cells - IPSB-18 and C) glioblastoma cells - IPTP. Representative MTT viability assay histograms for various treatments: D) tangeretin and IPLD (no effect), E) tangeretin and IPSB-18 (IC 50 value - $11 \mu \mathrm{g} / \mathrm{ml}), F)$ nobiletin and IPSB-18 (no effect) G) limonin and IPSB-18 (no effect), H) naringin and IPTP (no effect), I) elderberry extract and IPSB-18 (no effect), J) bilberry extract and IPTP (no effect), $K)$ chokeberry extract and IPTP $\left(I C_{50}\right.$ value $\left.-30 \mu \mathrm{g} / \mathrm{ml}\right)$. Data represent mean $\pm S D$ from three independent experiments. 
spheroids (IPSB-18 with IPSB-18, IPTP with IPTP or UPES with UPES) were used as controls.

For the fluorescent dye staining of the spheroids, 2 probes were used. The green CellTracker CMFDA (5-chloromethylfluorescein diacetate) has an absorption maximum at $492 \mathrm{~nm}$ and emission maximum at $517 \mathrm{~nm}$ (product information). The orange CellTracker CMTMR (5-(and-6)-(((4-chloromethyl)benzoyl)amino)tetramethylrhodamine has an absorption maximum at $541 \mathrm{~nm}$ and an emission at $565 \mathrm{~nm}$ (product information). The difference in fluorescence emission wavelength between the probes makes them easily separable by specific fluorescence filter optics.

Stock solutions of $10 \mathrm{mM}$ CellTracker green and orange were prepared in DMSO, diluted to $25 \mu \mathrm{M}$ in complete medium and used for cell labelling. Spheroids were collected from the agar coated culture Petri dish, placed into a clean 6-well plate, where two spheroids were placed in each well and $2 \mathrm{ml}$ of $25 \mu \mathrm{M}$ CellTracker green (used to stain normal brain aggregates) or orange (used to stain tumour spheroids) solution was added to each well and the spheroids. After $30 \mathrm{~min}$ incubation at growth conditions, the tracker solution was replaced with $2 \mathrm{ml}$ of complete medium and incubated for further $30 \mathrm{~min}$. During this period, the chloromethyl groups of the dye undergo modification or are secreted from the cell. Finally, the spheroids were washed twice with complete medium and put into confrontation in a 96-well plate base coated with agar in order to attach with each other. The confrontations of the brain aggregates with the tumour spheroids were analysed at a magnification of $\times 5$ using z-stacks with an inverted Zeiss Axiovert microscope. Suitable software (Improvision) was used for detection. In order to detect the green CellTracker, GFP $(525 \mathrm{~nm})$ filter optics were used. Similarly, to detect the orange CellTracker, Rhodamine $(650 \mathrm{~nm})$ filter optics were used. The spheroid co-cultures, either treated or untreated with tangeretin were analysed and compared.

Statistical analysis. The absorbance values from the MTT viability assay were analysed using StatsDirect and Microcal (Origin) programmes. Data from all the wells $(n=6)$ at each concentration of the different polyphenols was expressed as a percentage of the positive control (untreated cells - $100 \%$ viable). $\mathrm{The} \mathrm{IC}_{50}$ was estimated from the dose-response curve. Statistical significance of differences between samples treated with the polyphenols and positive controls were determined by Student's $t$-test. Means \pm SD were plotted. The $\mathrm{x}$-axes for the histograms were sometimes nonlinear to avoid bunching of high-dilution data points.

\section{Results}

Cytotoxic properties: tangeretin and chokeberry extract decreased viability of both HGG cell lines. In order to determine the $\mathrm{IC}_{50}$ value (the concentration at which $50 \%$ of cells are non-viable), we treated the HGG cells (IPSB-18 at passage 33 and IPTP at passage 14) and normal human astrocytes (IPLD at passage 4) with each polyphenol at a small range of concentrations $(5 \mu \mathrm{g} / \mathrm{ml}-40 \mu \mathrm{g} / \mathrm{ml})$ initially and then, at a wider range $(1 \mu \mathrm{g} / \mathrm{ml}-1000 \mu \mathrm{g} / \mathrm{ml})$. Figure $2 \mathrm{~A}$ $\mathrm{C}$ show phase contract micrographs of the 3 cell cultures studied. Figure 2D-K represent selected MTT viability assay histograms for each polyphenolic compound. The normal astrocytes (IPLD) were unaffected by every agent tested at all concentrations, including tangeretin (Figure 2D). The $\mathrm{IC}_{50}$ value for tangeretin was estimated to be $11 \mu \mathrm{g} / \mathrm{ml}$ and similar for both HGGs as seen in Figure 2E (IPSB-18). The other citrus flavonoid, nobiletin, which is very similar in chemical structure to tangeretin (Figure $1 \mathrm{~B}$ and $\mathrm{C}$, respectively) did not exhibit any cytotoxic effect on $\mathrm{HGG}$ cells at all (Figure 2F - IPSB-18). The remaining 2 citrus flavonoids, naringin and limonin also failed to exhibit any cytotoxic effects on glioma cells (Figure 2G - IPSB-18 and Figure $2 \mathrm{H}-$ IPTP).

Of the 3 berry extracts tested, elderberry extract (Sambucus nigra) and bilberry extract (Vaccinum myrtilus) did not affect the viability of the cells, even at the highest concentration, $1000 \mu \mathrm{g} / \mathrm{ml}$ (Figure 2I - IPSB-18 and Figure 2J - IPTP, respectively). The $\mathrm{IC}_{50}$ value determined in both IPTP (Figure 2K) and IPSB-18 for Chokeberry extract (Aronia melanocarpa) was $30 \mu \mathrm{g} / \mathrm{ml}$. Collectively, these results indicate that none of the polyphenols are toxic to normal astrocytes but only tangeretin and chokeberry extract show inhibition of viable HGG cells. Hence, all subsequent experiments were conducted with tangeretin and chokeberry extract at their $\mathrm{IC}_{50}$ values $(11 \mu \mathrm{g} / \mathrm{ml}$ and $30 \mu \mathrm{g} / \mathrm{ml}$, respectively) unless otherwise stated.

Effects on mediator of invasion: CD44 expression was downregulated by tangeretin and chokeberry extract. Immunocytochemistry data show that both HGG cell lines tested had similar results. Figure 3A shows high levels of CD44 expression in IPTP cells. The expression of CD44, a mediator of invasion, was reduced when the cells were treated with 11 $\mu \mathrm{g} / \mathrm{ml}$ tangeretin (Figure $3 \mathrm{~B}$ ) and $30 \mu \mathrm{g} / \mathrm{ml}$ chokeberry extract (Figure 3C). A series of duplicate flow cytometry analyses (Figure 3D-G) performed were in agreement with these qualitative results. Figure $3 \mathrm{E}$ shows CD44 positive cells (untreated) for IPTP. The shift of the peaks indicated a reduction of $10 \%$ and $50 \%$ in the expression level of CD44 when treated with tangeretin and chokeberry extract, respectively (Figure $3 \mathrm{~F}$ and $3 \mathrm{G}$, respectively).

Effects on other mediators of invasion: Gene expression of MMPs, TIMPs and EGFR was down-regulated by tangeretin and chokeberry extract

Matrix metalloproteases (MMPs), particularly MMP-2 and MMP-14, their inhibitors (TIMPs) and EGFR have been implicated in glioma invasion. Qualitative real-time PCR was used to profile RNA expression of various MMPs and their TIMPs. Cell cultures were either untreated or treated with tangeretin or chokeberry extract. MMP-9, MMP-16 and MMP-25 were not detected in IPTP and IPSB-18 cells.

The gene expression profiles (relative RNA levels) shown in Figure 4A-I are in descending order. Invariably, chokeberry extract treated cells showed the most noticeable effects than tangeretin. Figure 4A shows the highest relative RNA levels in 
A
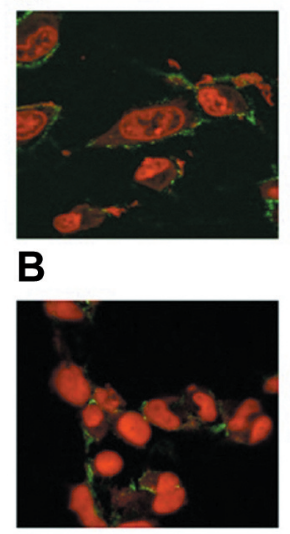

C

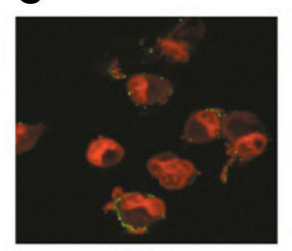

D

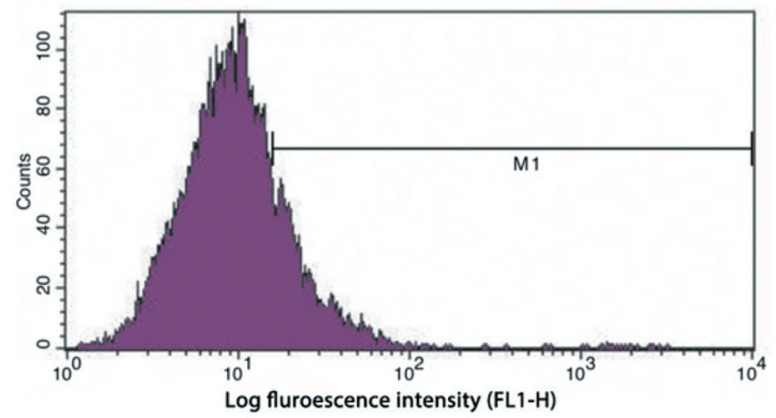

E
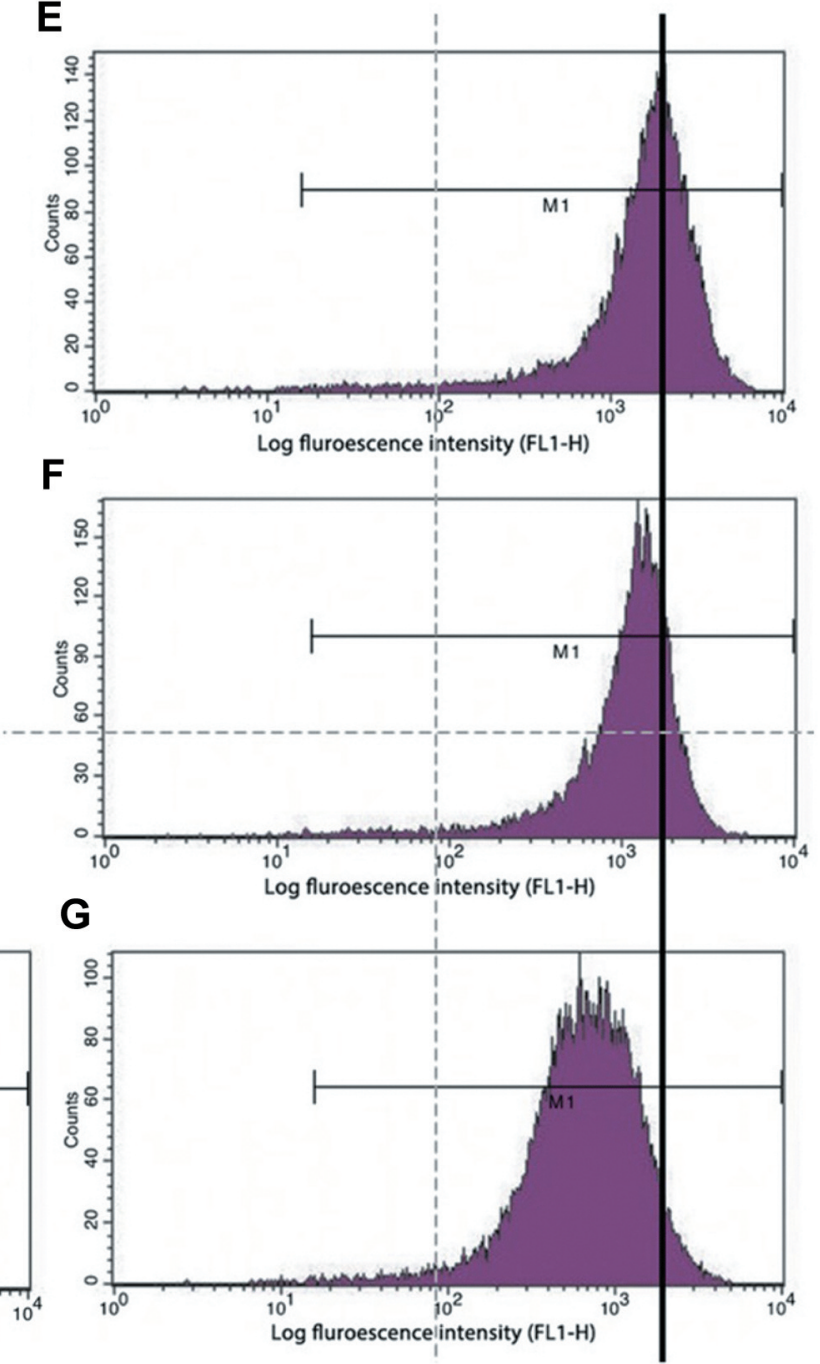

Figure 3. Effect of polyphenols on the reduction of CD44 positive cells. Representative fluorescence immunostaining for untreated IPTP cell cultures A) showing positivity for CD44 (green). The nucleus was labelled with propidium iodide (PI). Reduction of CD44 positive cells were seen when treated for $48 \mathrm{~h}$ with $B$ ) tangeretin and $C$ ) Chokeberry extract. D-G) Corresponding flow cytometric analysis confirmed immunocytochemistry results. D) Untreated cells (FITC only), E) CD44 positive cells. F) and G) a reduction in the expression level of CD44 positive cells was seen by $10 \%$ and $50 \%$ when treated with tangeretin and chokeberry extract, respectively. The M1 stats marker was applied to all samples. FLI: Log fluorescence intensity; counts: relative cell numbers.

untreated cells of the membrane-type MMP: MMP-14 $(20,000)$. Remarkably, when cells were treated with chokeberry extract at the $\mathrm{IC}_{50}$ concentration $(30 \mu \mathrm{g} / \mathrm{ml})$ there was a reduction in MMP-14 RNA expression by nearly $90 \%$. Cells treated with tangeretin showed a reduction of approximately $75 \%$. The RNA expression of EGFR in untreated cells was 500 and reduced to half this level with chokeberry extract. Even though the RNA levels of MMP-2, TIMP-1 and TIMP-2 were considerably lower in untreated cells (around 50), chokeberry extract was most effective in reducing this; by more than $60 \%$ (Figure 4C, D and E, respectively).
The next 3 profiles (Figure 4F-H) showed that although the untreated cells express very low RNA levels of MMP15, MMP-24 and TIMP-3 (15-7.5), chokeberry extract was still most effective. TIMP-4 gene expression was negligible $(0.05)$ in the high-grade glioma cells (Figure 4I) and any change with treatment was not very noticeable compared to all the other profiles studied.

Inhibition of invasion by tangeretin and chokeberry extract - 2D assay. Inhibition of 2D invasion of monolayers of cells (IPSB-18 and IPTP) was evaluated using 24-well Transwell 
A

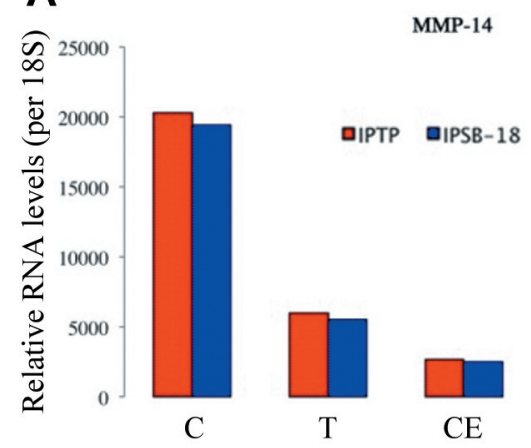

D

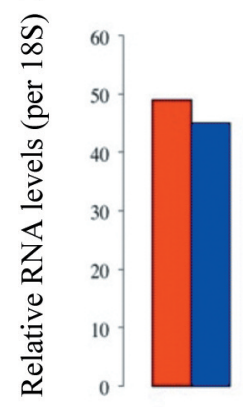

C
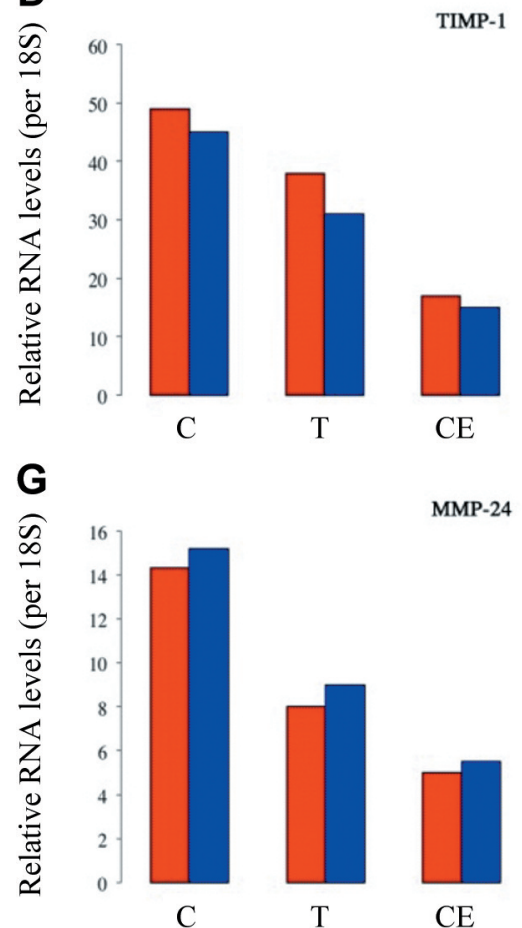

CE

MMP-24

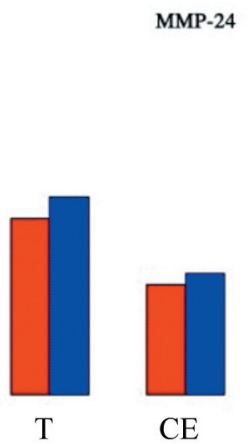

$\mathrm{T}$
B

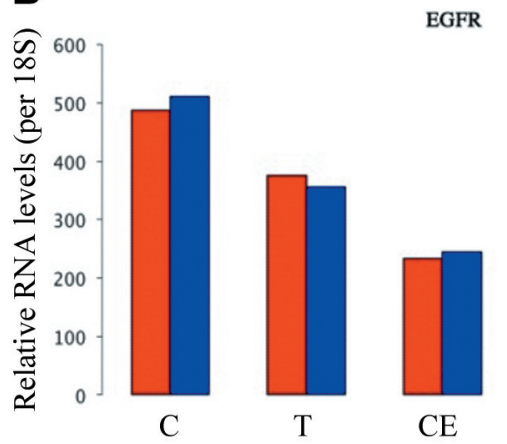

E

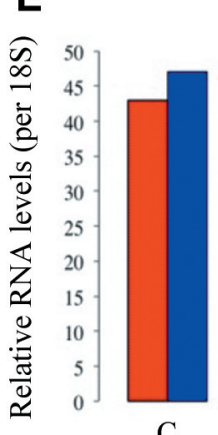

$\mathrm{H}$

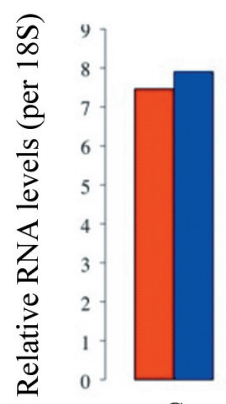

$\mathrm{C}$

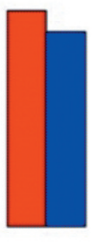

$\mathrm{T}$
C

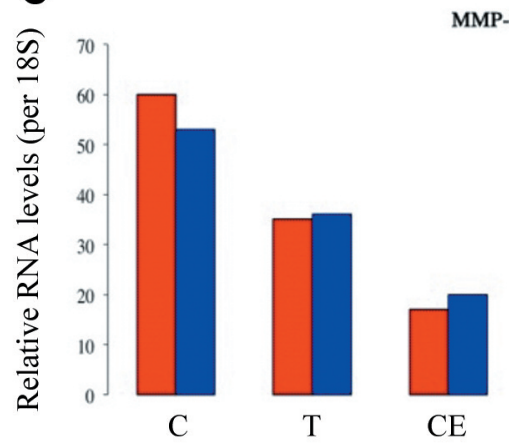

F

TIMP-2

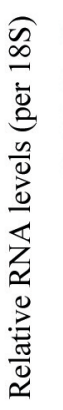

T

CE

TIMP-3

I

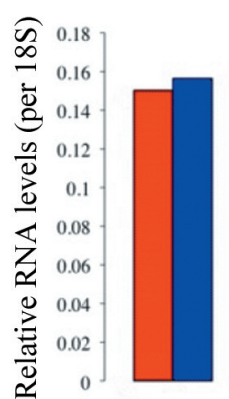

C
$\mathrm{T}$

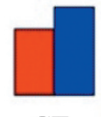

CE

TIMP-4

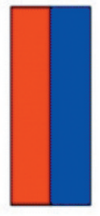

CE

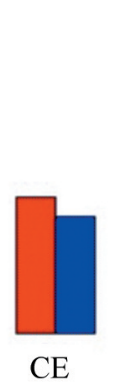

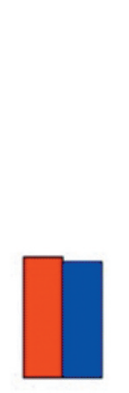

$\mathrm{T}$
MMP-15

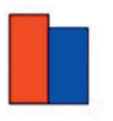

CE

Figure 4. Levels of MRNA expression of MMPs, TIMPs and EGFR in IPSB-18 and IPTP cells using RT-PCR. Gene expression was reduced most effectively with chokeberry extract than tangeretin, generally as seen with A) MMP-14, B) EGFR, C) MMP-2, D) TIMP-1, E) TIMP-2, F) MMP15, G) MMP-24, H) TIMP-3 and I) TIMP-4. The y-axis for each gene corresponds to the relative mRNA levels normalized to $18 S \mathrm{rRNA}$. The $x$-axis represents untreated cells $(C)$; cells treated with tangeretin $(T)$ or with chokeberry extract $(C E)$.

units after cells were treated at doses corresponding to $\mathrm{IC}_{25}$, $\mathrm{IC}_{50}$ and $\mathrm{IC}_{75}$ values for tangeretin $(5 \mu \mathrm{g} / \mathrm{ml}, 11 \mu \mathrm{g} / \mathrm{ml}$ and $35 \mu \mathrm{g} / \mathrm{ml}$ respectively) or chokeberry extract (17 $\mu \mathrm{g} / \mathrm{ml}, 30$ $\mu \mathrm{g} / \mathrm{ml}$ and $43 \mu \mathrm{g} / \mathrm{ml}$, respectively). Figure $5 \mathrm{~A}-\mathrm{C}$ represents images of IPSB-18 cells that have invaded the Matrigel to the lower porous membrane surface. The numbers of cells which invaded the filter were reduced under the different treatment regimens. The corresponding percentage invasion was calculated from the mean cell numbers counted in 5 fields for treated cells compared with untreated cells (control). The histograms for IPSB-18 in Figure 5D illustrate that chokeberry extract and tangeretin had comparable reduction in mean percentage inhibition (by 32\%) at their $\mathrm{IC}_{25}$ values but the former was more effective at higher values of $\mathrm{IC}_{50}$ and $\mathrm{IC}_{75}$ ( $73 \%$ and $91 \%$ respectively). The data were statistically significant $(p<0.05)$. Similar results for IPTP cells are presented in Figure 5E-H. In both gliomas, chokeberry extract had a greater anti-invasive potential than the citrus flavonoid.

Inhibition of invasion by tangeretin in spheroid co-cultures $-3 D$ assay. Corroboration of the anti-invasive potential seen 
A

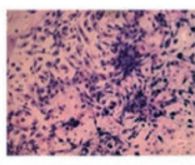

B

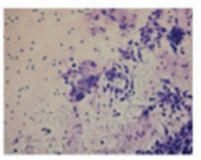

C

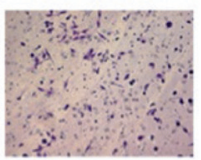

E

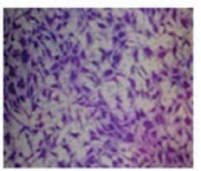

F

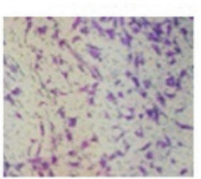

G

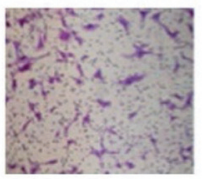

D

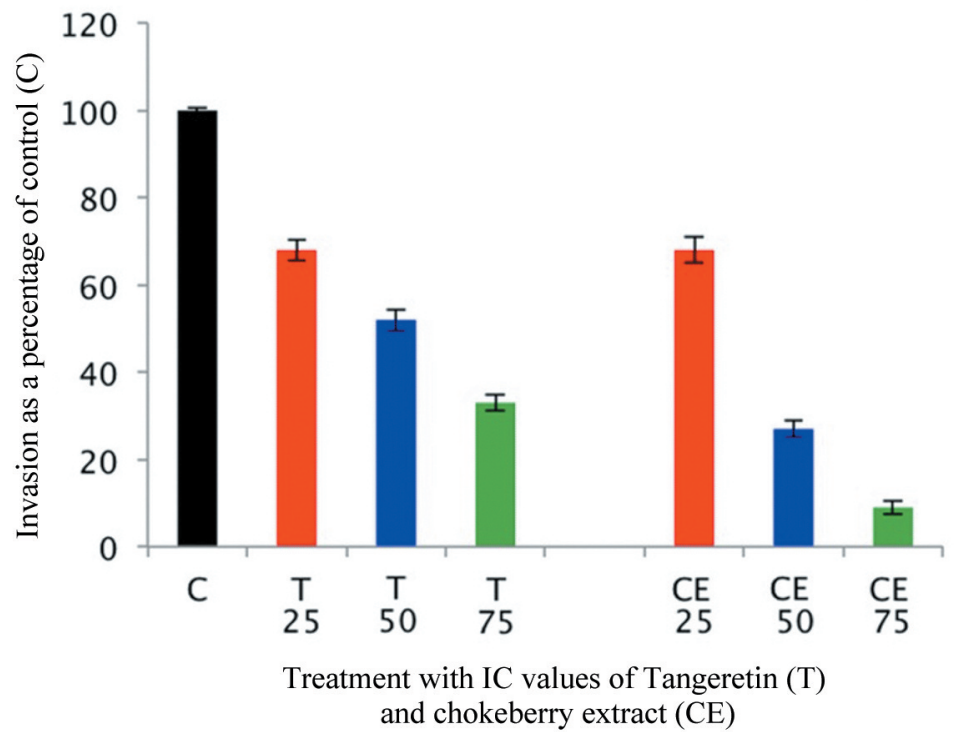

$\mathbf{H}$

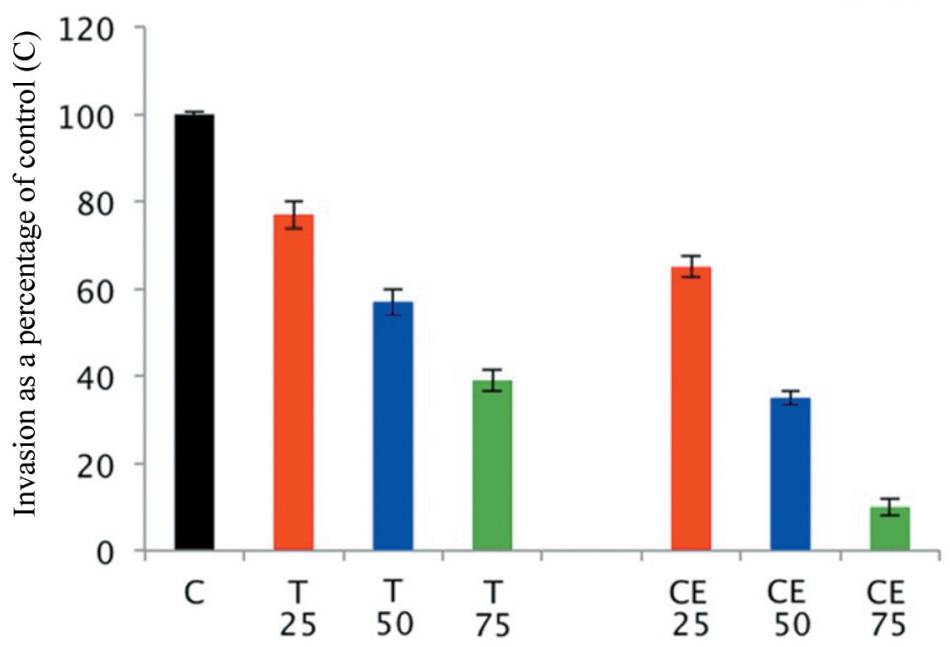

Treatment with IC values of Tangeretin (T) and chokeberry extract (CE)

Figure 5. Inhibition of cell invasion in vitro assessed by $2 D$ Transwell Boyden chamber assay. Representative images (magnification $\times 63$ ) of lower side of the filter shows violet stained IPSB-18 cells: Number of cells which invaded through the matrigel-coated polycarbonate membrane filter were accordingly reduced under the different treatment regimens. A) untreated (control), treated with $B$ ) tangeretin and C) chokeberry extract. $D$ ) Histograms of the mean invasion of IPSB-18 cells treated at $I C_{25}, I C_{50}$ and $I C_{75}$ values with Tangeretin (T) or chokeberry extract (CE) as a percentage of the untreated or control cells $(C)$. E-H) Similarly, corresponding results for IPTP suggest inhibition of cell invasion is generally more effective with chokeberry extract than tangeretin.

in the 2D Invasion assay was demonstrated in representative micrographs of confronting spheroids using a Zeiss Axiovert microscope with z-stack (Figure 6A-F). The green and Orange CellTrackers were detected with GFP (535 nm) and
Rhodamine $(650 \mathrm{~nm})$ filter optics, respectively. The spheroid co-cultures, either untreated or treated with $11 \mu \mathrm{g} / \mathrm{ml}$ tangeretin only, were analysed daily after incubation in a confrontation assay for up to 14 days. 
A

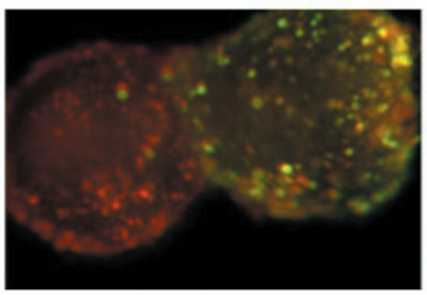

D

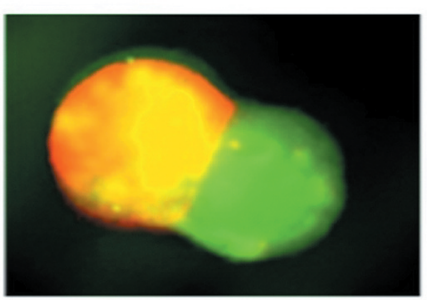

B

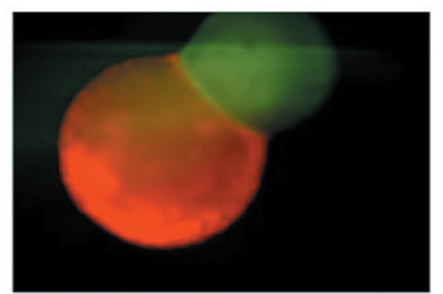

E

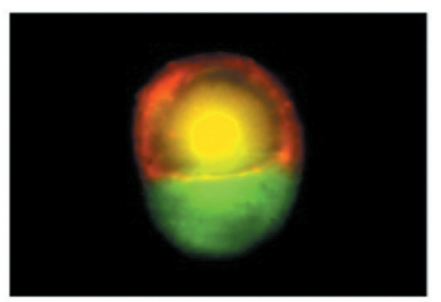

C

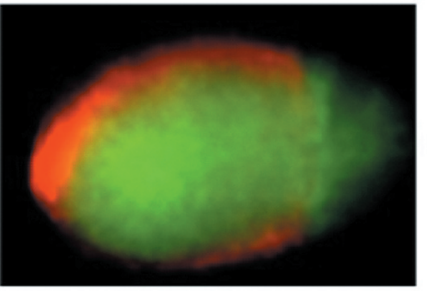

F

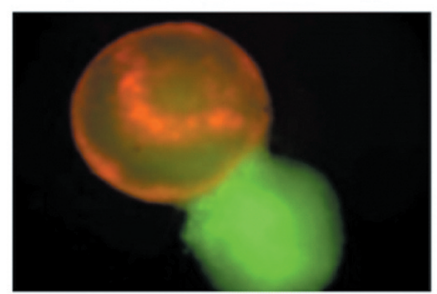

Figure 6. Micrographs showing confronting spheroids in a 3D invasion assay with or without treatment with $11 \mu \mathrm{g} / \mathrm{ml}$ tangeretin, incubated for up to 14 days. Isolated spheroids were exposed to either orange cell tracking dye for tumour (IPSB-18 or IPTP) or green for normal astrocyte aggregates (UPES). For confrontation between similar types, one spheroid had orange tracker and the other, green. Dynamics of confrontation were monitored using fluorescent trackers on individual cells. Confrontations between: A) Untreated: 2 similar spheroids - normal brain aggregates (UPES), individual cells can be tracked in both directions (day 2). B) Treated: 2 tumour spheroids (IPSB-18) - inhibition of invasion by tangeretin seen and initial conformation maintained. C) Untreated: tumour (IPTP) and normal (UPES) spheroids - invading cells seen and merger of the two fluorochromes (day 7). D) Treated: tumour (IPTP) and normal (UPES) spheroids - no invasion seen; clear borderline present between spheroids (day 14). E) Untreated: tumour (IPSB-18) and normal (UPES) - cells seen beginning to invade (day 3). F) Treated: tumour (IPSB-18) and normal (UPES) - invasion is inhibited; no merger between spheroids (day 5). The images were produced with a Zeiss Axiovert microscope (magnification $\times 5$ ) with z-stacks.

For every confrontation between 2 spheroids studied, isolated spheroids were exposed to either orange or green cell tracking dyes. As expected with controls, when 2 untreated and similar human astrocyte aggregates (UPES) were confronted (Figure 6A), there was fusion of the spheroids at day 5 of incubation. Additionally, when 2 untreated glioma cell spheroids (IPSB-18) were cocultured, there was dynamic interaction of cells in both directions as seen by the tracking of fluorescent orange and green dyes. However, spheroid confrontations treated with tangeretin reacted differently; although the green/red tracked spheroids conjugated, there was a distinct green red border between the spheroids, with each aggregate maintaining its initial spherical form over the course of the experiment (Figure 6B).

For confrontations between tumour and normal astrocyte aggregates, isolated spheroids were exposed to cell tracking dyes: orange for the tumour cells (IPTP) and green for the normal human astrocytes (UPES). Visualisation of the confrontations between these spheroids showed movement of tumour cells (untreated) into the normal brain aggregates and individual normal astrocytes could be identified in the tumour spheroids. Fusion was seen between the cocultures at 2 days and was more obvious with incremental days e.g. 7 days of incubation (Figure 6C). For tumour cells treated with tangeretin, there was no apparent exchange of cells between spheroids as seen at day 14 of incubation (Figure $6 \mathrm{D})$. There was no merger and the spheroids maintained their initial conformation indicating inhibition of invasion. Similar results for confrontation between IPSB-18 and UPES are represented in Figure $6 \mathrm{E}$ for untreated cells at day 3 of incubation. Additionally, treated tumour spheroids did not merge with brain aggregates as seen in Figure 6F corresponding to 5 days of incubation.

\section{Discussion}

Over the years our research has had a considerable focus on parameters of HGG invasion, particularly its mediators such as cell adhesion molecules (e.g. integrins, CD44) (4), proteases (MMPs and their inhibitors, TIMPs) (22) as well as EGFR (tyrosine kinase inhibitor) (23). Our research has also extended to investigate the anti-invasive potential of micronutrients such as selenium and various polyphenols $e . g$. red grape seed extract, red clover extract, curcumin from turmeric and lycopene from tomatoes (7-10).

As a part of a very large study where we evaluated the biological behaviour of a wide range of micronutrients, mentioned above, we have demonstrated here the in vitro 
effects of polyphenols from a number of citrus fruits and berries. Our present findings indicate that tangeretin and chokeberry extract are not toxic to normal brain cells and are the best candidates for therapeutic intervention for brain tumour management. The latter has better anti-invasive properties generally than the former. Indeed, further supportive evidence using 3D multi-cell population sophisticated complex human in vitro systems is merited.

There has been considerable increased interest in the last 3 decades in nutraceutical intervention, particularly polyphenols, for cancer. These naturally occurring products and their metabolites possess a broad spectrum of structural variation, which is related to an equally wide range of antiglioma effects. Molecular mechanisms have been proposed for multiple effects of some polyphenols on the induction of apoptosis, inhibition of proliferation, invasion, and angiogenesis as well as modulation of multidrug resistance (14). Polyphenols are usually present in glycosylated forms with one or more sugar residues conjugated to a hydroxyl group of the aromatic ring (Figure 1), which is why they are poorly absorbed after ingestion. Their low bioavailability has been considered to be a hurdle, but the use of their nanoformulation has shown promising results (24). For these agents to be of therapeutic value to HGG patients, it is essential for them to cross the blood-brain barrier (BBB). We have shown that tangeretin traverses this barrier in the rat brain (25), and similarly, others have shown that dietary anthocyanins found in chokeberry extract cross the BBB (26). Moreover, human studies have indicated that the chokeberry extract used in the present study (from Artemis International, Inc.) is well tolerated (27).

In terms of chemical structure, tangeretin (citrus methoxyflavone) is a small water- soluble flavonoid with a molecular weight of $372 \mathrm{Da}$. In contrast, chokeberry extract contains a number of polyphenols including phenolic acid (chlorogenic acid), 2 catechins [(-)-epicatechin, (+)catechin], a flavone (rutin) and 3 anthocyanins (cyanindin3-galactoside, cyanindin-3-arabinoside, cyanindin-3glucoside-xyloside). Santos et al. (28) demonstrated antiproliferative, pro-apoptotic and morphogenic effects of one of the constituents of chokeberry extract, rutin (quercetin-3rutinoside), on an established human GBM cell line (GL-15) suggesting its multiple anti-cancer effects. It is not surprising that our current study indicates that chokeberry extract has more a anti-invasive potential than tangeretin. Moreover, when a single or a combination of polyphenols are used (even at low concentrations) with or without standard therapy, they can exert synergistic and additive effects on multiple signalling pathways. They can also potentiate cytotoxicity of chemotherapy. We have previously reported such an enhanced effect on gemcitabine with an $\mathrm{IC}_{75}$ value of chokeberry extract in an aggressive pancreatic ductal adenocarcinoma (PDAC) cell line (29).
In the present study, $\mathrm{IC}_{50}$ values of tangeretin $(11 \mu \mathrm{g} / \mathrm{ml})$ and chokeberry extract $(30 \mu \mathrm{g} / \mathrm{ml})$ were determined in the HGG cells. Nobiletin, naringin, limonin, elderberry extract and, bilberry extract, were excluded from further investigation. This is because an $\mathrm{IC}_{50}$ value could not be determined for them in the wide range of concentrations chosen (up to $1,000 \mu \mathrm{g} / \mathrm{ml}$ ). In contrast, our preliminary studies showed that tangeretin and nobiletin had differential effects on in vitro adhesion, invasion and motility in 7 brain tumour cell lines (including low grade gliomas and an ependymoma) (8). Although a given polyphenol can exhibit cytotoxic effects and target more than one biological feature in some cancer cell lines, it is not unusual for it to have no effect at all in others.

It is not possible to compare $\mathrm{IC}_{50}$ values for chokeberry extract with those used by other workers as we are the only ones who have previously published any such data on gliomas (10). Indeed, we reported this value to be $200 \mu \mathrm{g} / \mathrm{ml}$ in an established GBM cell line (U373), which was not unexpectedly higher than the $30 \mu \mathrm{g} / \mathrm{ml}$ (for our short term, low passage cultures) in the present study. Generally, established cell lines tend to be more resistant to the cytotoxic effects of polyphenols compared to short-term cultures. Since, with increments of passage numbers, their cell population becomes less heterogeneous.

Neoplastic cells are thought to stimulate host fibroblasts to produce hyaluronic acid (HA), which is a component of ECM and found in high concentrations in the brain (30). Both HA and the cell adhesion molecule, CD44 are implicated in glioma invasion. Once HA is secreted into the stroma, it undergoes hydration, thereby opening up the extracellular space to permit entry of invading neoplastic cells. Migration is facilitated through invading cells adhering transiently to HA by CD44 receptor/HA binding. Once the new host tissue is invaded, neoplastic cells produce hyaluronidase to break down the HA molecules and a proangiogenic product for their survival (31). CD44 is known to be over-expressed in gliomas and our data show that its levels are down-regulated when cells are treated with tangeretin. However, chokeberry extract was most effective at down-regulating CD44, the major receptor for HA. The possible mode of action could be reduction of HA:CD44 interactions and hence, inhibition of glioma invasion. Annabi et al. (32) have proposed inhibition of RhoA/ROK (Rhoassociated kinase)-mediated CD44 cell surface shedding from an established GBM cell line (U-87) by a catechin. This mechanism was thought to be regulated through a complex MMP-14/CD44/caveolin interaction at the leading edges of invading cells.

Considerable evidence is documented for the role of proteases (e.g. MMP-2 and the Membrane-type MMP, MMP14) in malignant brain tumour invasion (19, 22). In accordance with previous studies, our data show differential 
expression of MMPs and TIMPs in the 2 high grade gliomas studied. Down-regulation of most of the genes studied was seen with treated cells, generally. Interestingly, MMP-14 gene, which is the most highly expressed, was more strongly down-regulated by chokeberry extract than tangeretin. A similar effect was seen with MMP-2, which is also associated with invasion and angiogenesis. The mechanism involved for the activation of MMP-2 is well documented. It forms a ternary complex with MMP-14 and TIMP-2, such that the $\mathrm{N}$-terminal domain of the latter binds to and inhibits MMP-14, whereas the C-terminal domain of the same TIMP2 molecule binds the hemopexin-like domain of MMP-2.

Both MMPs and their inhibitors, TIMPs, are known to play other roles apart from those of invasion and angiogenesis (33). Of the 4 TIMPS, TIMP-1 and -2 had considerably low, but similar, expression levels. In contrast, TIMP-3 was minimally expressed and is also thought to promote apoptosis. It is likely that the overall downregulation of MMPs and TIMPs by the polyphenols in this study may affect a variety of other functions in addition to invasion. MMPs facilitate invasion and TIMPs inhibit MMPS. It is a well-established biological phenomenon that although MMPs and TIMPs have divergent roles, their expression levels are in synch and go up and down together.

EGFR gene amplification is common in primary GBMs and linked with the invasive behaviour of these neoplasms as well as with increased angiogenesis. Additionally, EGFRvIII, a mutant form of EGFR occurs in approximately $55 \%$ of EGFR-over-expressing GBMs (5). EGFR belongs to the tyrosine kinase receptor family, which act as receptors for cytokines, growth factors, hormones and other extracellular signalling molecules. The receptors are activated by ligands followed by signalling through 3 main downstream pathways: Ras mitogenic (Ras/MAPK/ERK), Jak Stat or Ras phosphoinositide-3-kinase (Ras/PI13K/AKT). RNA levels of $E G F R$ were highly expressed in the glioma cells in the present study and down-regulated when treated with each of the polyphenols. Again, chokeberry extract was most effective. This might explain how treated cells affect EGFR and the signalling pathway, by inhibiting invasion as well as angiogenesis.

We observed that tangeretin and chokeberry extract have the potential to inhibit the inherent invasive behaviour of glioma cells through Matrigel in the 2D invasion assay. Chokeberry had the greatest effect. This is consistent with the results seen with the down-regulation of mediators of invasion: CD44 expression (flow cytometry and immunocytochemistry) as well as MMPs, TIMPs and EGFr (RT-PCR).

The 2D assay invasiveness of the glioma cells was consistent with results shown in the $3 \mathrm{D}$ confrontation models between glioma cell spheroids treated with tangeretin and human astrocyte aggregates studied at different time points. This model has the advantage of studying the pattern and kinetics of both tumour and normal cell movement in a three-dimensional confrontational system. Microscopic analysis of the confrontations between tumour spheroids (treated with tangeretin) with non-tumour spheroids demonstrated inhibition of cell movement directed to the control aggregates. After 5-7 days, a border line between the two spheroids was clearly visible. In contrast, with cocultures of untreated cells, the two spheroids fused and merged into each other and individual cell movement could be observed in both directions after a 2-day incubation period. Then, complete amalgamation between the tumour and the host spheroids was seen at 10-14 days. Interestingly, non tumour cells from the brain aggregates were also visible within the tumour tissue, implying a dynamic process with active involvement between the surface molecules of the non-tumour cells and the molecules present on the surface of the tumour cells.

$3 \mathrm{D}$ co-culture models serve as intermediate systems between the monolayer 2D systems and more complex in vivo models. Indeed, the use of $3 \mathrm{D}$ in vitro models for studying glioma invasion provides a system that more closely reflects the microenvironment present in the neoplasm of origin. Recently, various 3D spheroid models have been reported by other workers to help better understand invasion by reproducing spatial organization and microenvironmental factors of in situ neoplasms $(34,35)$. Further experiments are merited using such sophisticated models in elucidating the cellular mechanism involved in the polyphenol-mediated control of glioma invasion.

\section{Conclusion}

Taken together, this study has demonstrated that tangeretin and chokeberry extract (Aronia melanocarpa) have the ability to down-regulate some of the mediators of invasion such as CD44, EGFR, matrix metalloproteinases, particularly MMP-14 and TIMPs. These polyphenolic compounds are also known to cross the BBB and affect various downstream signalling pathways for invasion. Moreover, our findings demonstrate that chokeberry extract has better anti-invasive potential than tangeretin and is a stronger therapeutic candidate for management of HGGs.

\section{Conflicts of Interest}

The Authors declare that they have no competing interests in relation to this study.

\section{Authors' Contributions}

HKR and GJP designed the study. RS and RWG provided surgical samples and reviewed the work. MC, SAM and DD contributed to experimental studies and data analysis. HKR wrote the manuscript. All Authors read and approved the final manuscript. 


\section{Acknowledgements}

The Authors would like to acknowledge Kyriaki Pantopoulou, Satinder K. Lall and Sholeh Keshavarz for their technical assistance in the laboratory. Mandeep Singh Rooprai is acknowledged for formatting all the figures.

\section{Funding}

Financial support for this study was provided by the late Dennis Roth (Have a Chance Inc., USA), Golden Charitable Trust and UK Brain Tumour Society, UK.

\section{References}

1 Louis DN, Perry A, Reifenberger G, von Deimling A, FigarellaBranger D, Cavenee WK, Ohgaki H, Wiestler OD, Kleihues P and Ellison DW: The 2016 World Health Organization Classification of Tumors of the Central Nervous System: A summary. Acta Neuropathol 131: 803-820, 2016. PMID: 27157931. DOI: $10.1007 / \mathrm{s} 00401-016-1545-1$

2 Stupp R, Mason WP, van den Bent MJ, Weller M, Fisher B, Taphoorn MJB, Belanger K, Brandes AA, Marosi C, Bogdahn U, Curschmann J, Janzer RC, Ludwin SK, Gorlia T, Allgeier A, Lacombe D, Cairncross JG, Eisenhauer E and Mirimanoff RO: Radiotherapy plus concomitant and adjuvant temozolomide for glioblastoma. N Engl J Med 352: 987-996, 2005. PMID: 15758009. DOI: 10.1056/NEJMoa043330

3 Hatoum A, Mohammed $\mathrm{R}$ and Zakieh $\mathrm{O}$ : The unique invasiveness of glioblastoma and possible drug targets on extracellular matrix. Cancer Manag Res 11: 1843-1855, 2019. PMID: 30881112. DOI: 10.2147/CMAR.S186142

4 Maherally Z, Smith JR, An Q and Pilkington GJ: Receptors for hyaluronic acid and poliovirus: a combinatorial role in glioma invasion? PLoS One 7: e30691, 2012. PMID: 22363471. DOI: 10.1371/journal.pone.0030691

5 Keller S and Schmidt MHH: EGFR and EGFRvIII promote angiogenesis and cell invasion in glioblastoma: combination therapies for an effective treatment. Int J Mol Sci 18, 2017. PMID: 28629170. DOI: 10.3390/ijms18061295

6 Jain KK: A critical overview of targeted therapies for glioblastoma. Front Oncol 8: 419, 2018. DOI: 10.3389/fonc.2018.00419

7 Rooprai HK, Christidou M and Pilkington GJ: The potential for strategies using micronutrients and heterocyclic drugs to treat invasive gliomas. Acta Neurochir (Wien) 145: 683-690, 2003. PMID: 14520549. DOI: 10.1007/s00701-003-0073-7

8 Rooprai HK, Kandanearatchi A, Maidment SL, Christidou M, Trillo-Pazos G, Dexter DT, Rucklidge GJ, Widmer W and Pilkington GJ: Evaluation of the effects of swainsonine, captopril, tangeretin and nobiletin on the biological behaviour of brain tumour cells in vitro. Neuropathol Appl Neurobiol 27: 29-39, 2001. PMID: 11299000. DOI: 10.1046/j.0305-1846.2000.00298.x

9 Rooprai HK, Kyriazis I, Nuttall RK, Edwards DR, Zicha D, Aubyn D, Davies D, Gullan R and Pilkington GJ: Inhibition of invasion and induction of apoptosis by selenium in human malignant brain tumour cells in vitro. Int J Oncol 30: 1263-1271, 2007. PMID: 17390030.

10 Abdullah Thani NA, Sallis B, Nuttall R, Schubert FR, Ahsan M, Davies D, Purewal S, Cooper A and Rooprai HK: Induction of apoptosis and reduction of MMP gene expression in the U373 cell line by polyphenolics in Aronia melanocarpa and by curcumin. Oncol Rep 28: 1435-1442, 2012. PMID: 22842701. DOI: $10.3892 /$ or.2012.1941

11 Abotaleb M, Samuel SM, Varghese E, Varghese S, Kubatka P, Liskova A and Büsselberg D: Flavonoids in cancer and apoptosis. Cancers (Basel) 11, 2018. PMID: 30597838. DOI: 10.3390/cancers 11010028

12 Sun L-R, Zhou W, Zhang H-M, Guo Q-S, Yang W, Li B-J, Sun Z$\mathrm{H}$, Gao S-H and Cui R-J: Modulation of multiple signaling pathways of the plant-derived natural products in cancer. Front Oncol 9: 1153, 2019. PMID: 31781485. DOI: 10.3389/fonc. 2019.01153

13 Niedzwiecki A, Roomi MW, Kalinovsky $\mathrm{T}$ and Rath M: Anticancer efficacy of polyphenols and their combinations. Nutrients 8, 2016. PMID: 27618095. DOI: 10.3390/nu8090552

14 Vengoji R, Macha MA, Batra SK and Shonka NA: Natural products: a hope for glioblastoma patients. Oncotarget 9: 2219422219, 2018. PMID: 29774132. DOI: 10.18632/oncotarget.25175

15 Erices JI, Torres Á, Niechi I, Bernales I and Quezada C: Current natural therapies in the treatment against glioblastoma. Phytother Res 32: 2191-2201, 2018. PMID: 30109743. DOI: 10.1002/ptr.6170

16 Rooprai HK, Ashkan K, Brazil L, Selway RP, Lodhi R, Aitchison KJ, Gullan RW and Beaney R: Role of a combination of seven micronutrients in the management of glioblastoma multiforme. Clin Oncol (R Coll Radiol) 27: 370-371, 2015. PMID: 25681869. DOI: 10.1016/j.clon.2015.01.010

17 Knott JCA, Edwards AJ, Gullan RW, Clarke TM and Pilkington GJ: A human glioma cell line retaining expression of GFAP and gangliosides, recognized by A2B5 and LB1 antibodies, after prolonged passage. Neuropathol Appl Neurobiol 16: 489-500, 1990. DOI: $10.1111 / \mathrm{j} .1365-2990.1990 . t b 01288 . x$

18 Nikkhah G, Tonn JC, Hoffmann O, Kraemer HP, Darling JL, Schachenmayr W and Schönmayr R: The MTT assay for chemosensitivity testing of human tumors of the central nervous system. Part II: Evaluation of patient- and drug-specific variables. J Neurooncol 13: 13-24, 1992. PMID: 1613536. DOI: 10.1007/BF00172942

19 Nuttall RK, Pennington CJ, Taplin J, Wheal A, Yong VW, Forsyth PA and Edwards DR: Elevated membrane-type matrix metalloproteinases in gliomas revealed by profiling proteases and inhibitors in human cancer cells. Mol Cancer Res 1: 333345, 2003. PMID: 12651907.

20 Albini A: Tumor and endothelial cell invasion of basement membranes. The matrigel chemoinvasion assay as a tool for dissecting molecular mechanisms. Pathol Oncol Res 4: 230-241, 1998. PMID: 9761943. DOI: 10.1007/BF02905254

21 Del Duca D, Werbowetski T and Del Maestro RF: Spheroid preparation from hanging drops: characterization of a model of brain tumor invasion. J Neurooncol 67: 295-303, 2004. PMID: 15164985. DOI: 10.1023/b:neon.0000024220.07063.70

22 VanMeter TE, Rooprai HK, Kibble MM, Fillmore HL, Broaddus WC and Pilkington GJ: The role of matrix metalloproteinase genes in glioma invasion: co-dependent and interactive proteolysis. J Neurooncol 53: 213-235, 2001. PMID: 11716072. DOI: $10.1023 / \mathrm{a}: 1012280925031$

23 Vouri M, Croucher DR, Kennedy SP, An Q, Pilkington GJ and Hafizi S: Axl-EGFR receptor tyrosine kinase hetero-interaction provides EGFR with access to pro-invasive signalling in cancer cells. Oncogenesis 5: e266-e266, 2016. DOI: 10.1038/oncsis. 2016.66 
24 Brglez Mojzer E, Knez Hrnčič M, Škerget M, Knez Ž and Bren U: Polyphenols: Extraction methods, antioxidative action, bioavailability and anticarcinogenic effects. Molecules 21, 2016. PMID: 27409600. DOI: 10.3390/molecules21070901

25 Datla KP, Christidou M, Widmer WW, Rooprai HK and Dexter DT: Tissue distribution and neuroprotective effects of citrus flavonoid tangeretin in a rat model of Parkinson's disease. Neuroreport 12: 3871-3875, 2001. PMID: 11726811. DOI: 10.1097/00001756-200112040-00053

26 Manolescu BN, Oprea E, Mititelu M, Ruta LL and Farcasanu IC: Dietary anthocyanins and stroke: A review of pharmacokinetic and pharmacodynamic studies. Nutrients 11, 2019. PMID: 31261786. DOI: $10.3390 /$ nu11071479

27 Kay CD, Mazza G, Holub BJ and Wang J: Anthocyanin metabolites in human urine and serum. Br J Nutr 91: 933-942, 2004. PMID: 15228048. DOI: 10.1079/bjn20041126

28 Santos BL, Silva AR, Pitanga BPS, Sousa CS, Grangeiro MS, Fragomeni BO, Coelho PLC, Oliveira MN, Menezes-Filho NJ, Costa MFD, El-Bachá RS, Velozo ES, Sampaio GP, Freire SM, Tardy M and Costa SL: Antiproliferative, proapoptotic and morphogenic effects of the flavonoid rutin on human glioblastoma cells. Food Chem 127: 404-411, 2011. PMID: 23140679. DOI: 10.1016/j.foodchem.2010.12.131

29 Thani NAA, Keshavarz S, Lwaleed BA, Cooper AJ and Rooprai HK: Cytotoxicity of gemcitabine enhanced by polyphenolics from Aronia melanocarpa in pancreatic cancer cell line AsPC1. J Clin Pathol 67: 949-954, 2014. PMID: 25232128. DOI: 10.1136/jclinpath-2013-202075

30 Pilkington GJ: Cancer stem cells in the mammalian central nervous system. Cell Prolif 38: 423-433, 2005. PMID: 16300654. DOI: 10.1111/j.1365-2184.2005.00358.x
31 Pilkington CJ: The role of the extracellular matrix in neoplastic glial invasion of the nervous system. Brazilian J Med Biol Res 29: 1159-1172, 1996. PMID: 9181059.

32 Annabi B, Bouzeghrane M, Moumdjian R, Moghrabi A and Béliveau R: Probing the infiltrating character of brain tumors: inhibition of RhoA/ROK-mediated CD44 cell surface shedding from glioma cells by the green tea catechin EGCg. J Neurochem 94: 906-916, 2005. PMID: 15992376. DOI: 10.1111/j.14714159.2005.03256.x

33 Groft LL, Muzik H, Rewcastle NB, Johnston RN, Knäuper V, Lafleur MA, Forsyth PA and Edwards DR: Differential expression and localization of TIMP-1 and TIMP-4 in human gliomas. Br J Cancer 85: 55-63, 2001. PMID: 11437402. DOI: 10.1054/bjoc.2001.1854

34 Oraiopoulou M-E, Tampakaki M, Tzamali E, Tamiolakis T, Makatounakis V, Vakis AF, Zacharakis G, Sakkalis V and Papamatheakis J: A 3D tumor spheroid model for the T98G Glioblastoma cell line phenotypic characterization. Tissue Cell 59: 39-43, 2019. PMID: 31383287. DOI: 10.1016/j.tice.2019.05.007

35 Leite DM, Zvar Baskovic B, Civita P, Neto C, Gumbleton M and Pilkington GJ: A human co-culture cell model incorporating microglia supports glioblastoma growth and migration, and confers resistance to cytotoxics. FASEB J 34: 1710-1727, 2020. PMID: 31914660. DOI: 10.1096/fj.201901858RR

Received December 23, 2020

Revised January 14, 2021

Accepted January 15, 2021 